\title{
A IMPLANTAÇÃO DOS COLÉGIOS ESTADUAIS EM FRANCISCO BELTRÃO NO CONTEXTO DO REGIME MILITAR ${ }^{1}$
}

Alisson Fernando Severgnini ${ }^{2}$ André Paulo Castanha ${ }^{3}$

\begin{abstract}
Resumo: O objetivo central do presente texto foi/é identificar as instituições escolares criadas em Francisco Beltrão-PR no período do regime militar. Para tanto nos cercamos de fontes documentais e bibliográficas, procuramos articular a análise ao contexto da criação das instituições e ao desenvolvimento nacional e local no período, bem como aos aspectos legais da organização educacional. Conseguimos identificar todas as instituições escolares estaduais criadas em Francisco Beltrão durante o período do regime militar. No entanto, não foi/é nosso objeto, neste momento, desenvolver estudos detalhados sobre as trajetórias destas instituições, mas sim situá-las em seu tempo histórico, deixando essas histórias abertas para estudos futuros.

Palavras-Chave: Instituições Escolares, Regime Militar, Colégios Estaduais, Francisco Beltrão.
\end{abstract}

\section{THE IMPLEMENTATION OF STATE SCHOOLS IN FRANCISCO BELTRÃO IN THE CONTEXT OF THE MILITARY REGIME}

\begin{abstract}
The main objective of this text was / is to identify the school institutions created in Francisco BeltrãoPR, during the military regime. Therefore, we surround ourselves with documentary and bibliographic sources, we seek to articulate the analysis to the context of the creation of institutions and to national and local development in the period, as well as to the legal aspects of educational organization. We managed to identify all state school institutions created in Francisco Beltrão, during the period of the military regime. However, it was not / is not our objective, at this moment, to develop detailed studies on the trajectories of these institutions, but rather to situate them in their historical time, leaving these stories open for future studies.
\end{abstract}

Keywords: School Institutions, Military Regime, State Colleges, Francisco Beltrão.

\section{LA APLICACIÓN DE LAS ESCUELAS ESTATALES EN FRANCISCO BELTRÃO EN EL CONTEXTO DEL RÉGIMEN MILITAR}

Resumen: El objetivo principal de este texto era/es identificar las instituciones escolares creadas en Francisco Beltrão-PR durante el régimen militar. Con este fin, nos rodeamos de fuentes documentales y bibliográficas, buscamos articular el análisis al contexto de la creación de instituciones y al desarrollo nacional y local en el período, así como a los aspectos legales de la organización educativa. Logramos identificar todas las instituciones escolares estatales creadas en Francisco Beltrão durante el período del régimen militar. Sin embargo, no era/es nuestro objetivo, en este momento, desarrollar estudios detallados sobre las trayectorias de estas instituciones, sino situarlas en su tiempo histórico, dejando estas historias abiertas para futuros estudios.

Palabras clave: Instituciones Escolares, Régimen Militar, Escuelas Públicas, Francisco Beltrão.

\section{Introdução}

\footnotetext{
${ }^{1} \mathrm{O}$ presente texto é uma versão revista e ampliada do artigo apresentado no III Seminário Internacional de Educação e da XXIII Semana Acadêmica do Curso de Pedagogia. Francisco Beltrão: Unioeste, 2019. Anais v.1. p. 641 - 659.

${ }_{2}^{2}$ Mestrando em Educação pela Universidade Estadual do Oeste do Paraná - UNIOESTE. Especialista em Filosofia e Sociologia, Supervisão, Orientação e Gestão Escolar e Psicopedagogia. Graduado em História e Pedagogia. Membro do Grupo de Pesquisa: História, Sociedade e Educação no Brasil - HISTEDOPR - GT local do HISTEDBR. Professor efetivo da Rede Municipal de ensino de Francisco Beltrão - PR. alissonfernando@hotmail.com.br

${ }^{3}$ Professor do Colegiado de Pedagogia e do Mestrado em Educação da UNIOESTE - Campus de Francisco Beltrão - PR. Membro do Grupo de Pesquisa: História, Sociedade e Educação no Brasil - HISTEDOPR - GT local do HISTEDBR. Doutor em Educação pela UFSCar e Pós-doutor na área de Filosofia e História da Educação pela UNICAMP. E-mail: andrecastanha66@gmail.com
} 
A região Sudoeste do Paraná, devido a sua colonização tardia, fruto de incertezas e disputas territoriais, demorou um pouco mais para se desenvolver em relação a outros territórios paranaenses. Somente na década de 1940, com a implantação da Colônia Agrícola Nacional General Osório (CANGO), que a região acelerou sua colonização e seu desenvolvimento.

Os benefícios oferecidos pelo Governo Federal impulsionaram a imigração, e a população do Sudoeste do Paraná cresceu muito nos anos seguintes.

Com o aumento progressivo da população, a educação passou a ser uma necessidade, e aos poucos, foram surgindo as primeiras escolas, organizadas e mantidas pela CANGO. Escolas municipais e estaduais. Os Colégios Estaduais foram criados conforme a demanda e exigências de níveis diferentes de instrução. Neste trabalho, apresentamos um levantamento das instituições escolares estaduais implantadas no município de Francisco Beltrão durante o período do Regime Militar.

Utilizamos, para este estudo, as metodologias de pesquisa bibliográfica e documental, por meio da análise de obras referentes ao regime militar, de trabalhos acadêmicos na área de história da educação, da legislação educacional vigente no período e dos Projetos Político Pedagógicos das instituições escolares estaduais. Nosso objetivo, é contextualizar o cenário histórico, político e educacional do período em que o Brasil esteve sob o Governo Militar, e, apresentar quais instituições de ensino estaduais foram implantadas em Francisco Beltrão no período.

$\mathrm{O}$ presente texto está dividido em três partes. Na primeira, apresentamos de forma sintetizada os elementos históricos que levaram a implantação do regime militar no Brasil em 1964. Procuramos entender, embora de forma rápida, quais eram os cenários de disputa política vigentes naquele momento, e, quais foram os motivos que levaram ao Golpe Militar.

Na segunda parte do texto, analisamos alguns aspectos da legislação educacional no país quando os militares assumiram o governo, também, perscrutamos a lei 4.978/64 que estabelecia o Sistema Estadual de Ensino do Paraná. Já dentro de uma elaboração mais afinada com a proposta do governo militar, estudamos também aspectos da lei 5.692/71, que estabelecia diretrizes para o ensino de $1^{\circ}$ e $2^{\circ}$ graus. Procuramos compreender as ligações dos dispositivos legais com os interesses governamentais regidos pela influência do capital internacional e da iniciativa privada no país.

$\mathrm{Na}$ terceira parte, caracterizamos algumas das principais instituições de ensino estaduais que foram fundadas no período do regime militar. Embora não tenhamos conseguido avançar, no escopo deste texto, em um aprofundamento de como cada uma destas instituições enfrentou o período, deixando aberta a porta de investigação para estudos futuros. 


\section{As Bases Históricas que Levaram ao Regime Militar no Brasil}

De acordo com Amador (2002), a década de 1960 apresentou um cenário bastante controverso para a educação no Brasil. Disputas ideológicas colocavam conservadores e progressistas liberais frente a frente, cada qual defendendo sua perspectiva. Em face das discussões em torno da elaboração da primeira lei de diretrizes e bases da educação nacional, estas duas correntes disputavam espaço no debate entre o ensino público e o privado. No entanto, de acordo com o mesmo autor, este debate que era acalorado nos palcos dos interesses de cada seguimento, não trazia, em nenhuma das duas posições, qualquer reflexão quanto a legitimidade do modelo político econômico vigente. Este modelo, para Amador (2002), era o principal motor das relações sociais, portanto, era nele que deveriam estar focadas as discussões e os rumos do país e da educação.

No período estava em vigor a lei constitucional de 1946, que tinha uma perspectiva de democratização e alimentava o populismo. Após a Segunda Guerra Mundial, esta linha vinha sendo adotada por vários países, especialmente na Europa, e era a tendência naquele momento. Segundo Amador (2002), no período, também era possível ver a consolidação ocidental da hegemonia do capitalismo Norte Americano, fortalecido pelos resultados obtidos na Segunda Grande Guerra. No oriente, no entanto, a União Soviética também se fortalecia com um modelo econômico estatal, força que vinha ganhando relevância desde a Revolução Russa de 1917.

Esta queda de braços estabeleceu a chamada Guerra Fria, levando os Estados Unidos a organizar estratégia de desenvolvimento industrial em países dependentes de sua economia. Para Amador (2002), o objetivo era controlar as forças produtivas destes países, mantendo-os como aliados por força de necessidade.

Este impulso promovido pelas tendências imperialistas encabeçadas pelos Estados Unidos proporcionou uma grande mudança de ordem econômica no Brasil nas décadas de 1940 e 1950, especialmente "[...] devido a decadência de uma economia agroexportadora, como vinha até então ocorrendo. Os sucessivos fracassos na política de exportação do café atestam estas mudanças" (AMADOR, 2002, p. 26).

Ainda de acordo com o mesmo autor, a influência do capital estrangeiro no Brasil, aos poucos, começou a mostrar "sua faceta de acumulação e perversidade" (AMADOR, 2002, p. 30). A parcela de lucros enviada para o exterior era completamente desproporcional e infundada, o Brasil exportava muito, mas não recebia proporcionalmente e ainda acumulava dívidas em transações comerciais e financeiras.

Entre os anos de 1946 e 1964, surgiram muitos movimentos e agremiações políticopartidárias que se opunham a esta prática que vinha sendo exercida, acirrando mais uma vez as disputadas ideológicas no país. De um lado, aqueles que defendiam uma total autonomia da 
economia brasileira, livrando de uma vez por todas o país da dependência internacional, e de outro, aqueles que assimilavam seus interesses com os norte-americanos, e que defendiam a ausência do estado na economia. O segundo grupo, segundo Amador (2002), eram, em geral, representantes da iniciativa privada.

Ainda de acordo com Amador (2002), o suicídio de Getúlio Vargas em 1954 foi consequência da pressão exercida sobre ele pelas crises políticas decorrentes de sua posição contra o monopólio internacional. Sucedendo Getúlio Vargas, tivemos a figura de Juscelino Kubitschek, presidente que, segundo o mesmo autor, entregou cargos de importante relevância do governo para representantes internacionais e privados. Esta parceria com o latifúndio e com o imperialismo concentrou renda e gerou grande inflação, fortalecendo ainda mais o setor estrangeiro.

Jânio Quadros assumiu em 1961 a presidência do Brasil, trazendo como vice João Goulart. Jânio, representava a base conservadora, já João Goulart, a ala mais progressista, por isso provocava medo naqueles que viam nele, a possibilidade de um fim do projeto imperialista, pois, era grande entusiasta dos interesses nacionais. Jânio passou a sofrer muitas pressões e renunciou ao cargo em agosto de 1961.

Antes de assumir a presidência, de acordo com Amador (2002), João Goulart ficou em uma espécie de sistema parlamentarista até que, um plebiscito popular, reestabeleceu o presidencialismo. O receio do capital estrangeiro e dos setores privados e conservadores de que os movimentos sindicais ganhariam força e trariam o comunismo para o Brasil, fizeram com que, em $1^{\circ}$ de abril de $1964^{4}$, o país sofresse um Golpe Militar.

As expectativas de acumulação de capital vivida pelas elites brasileiras daquele momento, segundo Germano (2000), vinham na contramão dos projetos populistas do estado, que pretendiam reformular as estruturas da sociedade brasileira. Organizações de trabalhadores, estudantes e outros representantes da sociedade civil repercutiram e influenciaram campanhas e diversos movimentos de conscientização. Instituições, sindicatos, ligas e até mesmo representantes da Igreja Católica se empenhavam em difundir a ideia de que era necessário reformular as estruturas da sociedade.

De acordo com Germano (2000), os fatos ocorridos em Cuba deram animo aqueles que pretendiam livrar-se da influência e do domínio dos Estados Unidos. Os Norte Americanos reagiram através de uma "aliança econômica para o progresso", onde os exércitos se tornaram

\footnotetext{
${ }^{4}$ De acordo com Capuchinho (2014), as movimentações militares começaram a acontecer no dia 31 de março de 1964, porém, até $1^{\circ}$ de abril, João Goulart ainda estava no poder. De acordo com a mesma autora, os defensores do regime decidiram comemorar a data de 31 de março para fugir das piadas referentes ao chamado "dia da mentira".
} 
ferramentas de ação anti-subversiva. No Brasil, segundo o mesmo autor, houve clara influência dos Estados Unidos nas ações golpistas e antidemocráticas do Regime Militar.

Para Germano:

[...] o Estado militar caracteriza-se pelo aumento da intervenção na esfera econômica, concorrendo decisivamente para o crescimento das forças produtivas do país, sob a égide de um perverso processo de desenvolvimento capitalista que combinou crescimento econômico com uma brutal concentração de renda (2000, p. 56).

De acordo com Amador (2002), a educação brasileira que vinha em um ritmo acelerado de evolução até aquele momento, tendo conseguido articular projetos bem estruturados de defesa da escola pública, bem como de relação do caráter educacional com os problemas de demanda social, com o Golpe Militar, acabaram sofrendo grande retrocesso. As vozes que se mantiveram firmes no início foram, aos poucos, sendo caladas pela opressão e pelo uso indiscriminado da tortura.

Os investimentos, de acordo com Germano (2000), eram insuficientes no financiamento da Escola Pública, sendo direcionados para os setores que favoreciam a acumulação do capital. Para o mesmo autor, o objetivo educacional do Regime Militar foi criar uma hegemonia ideológica de aceitação dos pressupostos e das propostas de desenvolvimento pregadas por eles.

\section{A Legislação Educacional no Período do Regime Militar}

No início do Regime Militar, estava vigente, no Brasil, a LDBEN 4.024, de 20 de dezembro de 1961, que estabeleceu normas para os níveis de ensino primário, médio e superior. Este tipo de legislação, segundo Marchelli (2014), é o preceito máximo do sistema de ensino no Brasil. De acordo com ela, sua função é regulamentar a constituição nas questões educacionais.

A diretriz estabelecia a educação primária obrigatória, como um direito de todos, ficando a cargo da família optar pelo gênero educativo mais pertinente a seus filhos. A lei determinava, ainda, o papel do Estado como responsável pela manutenção dos meios necessários para que fossem asseguradas as oportunidades educativas, igualmente, a todos os cidadãos. Estabelecia, também, sansões para aqueles que, excetuando-se as ressalvas previstas $^{5}$, não fizessem matricular e frequentar as aulas, àqueles sob sua tutela.

A formação dos adolescentes correspondia, na LDBEN de 1961, ao ensino de grau médio, segundo a legislação:

\footnotetext{
${ }^{5}$ De acordo com o Art. 30 da Lei 4024/61 estavam isentos da obrigatoriedade aqueles que comprovassem estado de pobreza dos pais ou responsáveis, insuficiência de escola, encerramento de matrículas e doenças ou anomalias graves da criança (BRASIL, lei 4.024 de 1961).
} 
Art. 34 - O ensino médio será ministrado em dois ciclos, o ginasial e o colegial, e abrangerá, entre outros, os cursos secundários, técnicos e de formação de professores para o ensino primário e pré-primário (BRASIL, lei 4.024 de 1961).

O disposto na lei, referente ao ensino secundário, estabelecia que o ciclo ginasial deveria ter quatro séries anuais e o colegial, um mínimo de três séries anuais. Cabia ainda, segundo o Art. 35, parágrafo segundo, ao Conselho Federal e aos Conselhos Estaduais relacionarem as disciplinas e definirem a "amplitude e o desenvolvimento dos seus programas em cada ciclo" (BRASIL, lei 4.024 de 1961).

O Art. 36 estabeleceu que era necessário comprovar "satisfatória educação primária" através de um exame de admissão para ingressar o ensino secundário. Previa, ainda, a legislação de 1961:

Art. 104. Será permitida a organização de cursos ou escolas experimentais, com currículos, métodos e períodos escolares próprios, dependendo o seu funcionamento para fins de validade legal da autorização do Conselho Estadual de Educação, quando se tratar de cursos primários e médios, e do Conselho Federal de Educação, quando de cursos superiores ou de estabelecimentos de ensino primário e médio sob a jurisdição do Governo Federal (BRASIL, lei 4.024 de 1961).

De acordo com Novaes (2010), este artigo permitia flexibilizar currículos e métodos de avaliação. O ensino secundário, por este caminho, ganhava possibilidades abrangentes de organização e de aplicação dos recursos educativos, cabendo, apenas aos professores e gestores escolares o trabalho de mediar os processos.

A partir daí, nada mais impedia que escolas de grau médio se estruturassem com autonomia para desenvolvimento de um padrão de ensino renovado e flexível. A única limitação é a própria capacidade de diretores e professores para se valerem dessa ampla liberdade (NOVAES, 2010, p. 22 -23).

No entanto, segundo a mesma autora, com o golpe militar diversas medidas foram tomadas para controlar e impedir atividades estudantis que fossem contra o regime ou, que não estivessem de acordo com os grupos apoiadores do golpe e do capital estrangeiro.

[...] o governo militar orquestrou uma série de ações que buscavam, em síntese, adequar à política e a organização educacional às determinações econômicas. Assim, o conjunto de medidas tomadas no período refletiu a intenção velada de criar um instrumento de controle e de disciplina sobre a comunidade estudantil e o operariado, possíveis opositores ao regime, a fim de garantir a ampliação da gestão de capital dos grupos hegemônicos que constituíram o apoio civil ao golpe, especificamente alguns setores da burguesia nacional e grupos estrangeiros (NOVAES, 2010, p. 23). 
No Paraná, em 05 de dezembro de 1964, foi aprovada a lei $n^{\circ} 4.978$, que estabeleceu o Sistema Estadual de Ensino. Esta lei, respeitou os dispositivos expressos na LDBEN, de 1961 e regulamentou o ensino no Estado. O Art. 97 estabeleceu multa para os pais cujos filhos não estivessem matriculados e frequentando a escola primária. A multa prevista era de $10 \%$ a $50 \%$ sobre o maior salário mínimo que estivesse em vigor no Estado. Já o Art. 99 obrigava os proprietários rurais que tivessem crianças em suas terras a manter escolas primárias, facilitar o acesso à escola ou "propiciar a instalação e funcionamento de escolas públicas em suas propriedades" (PARANÁ, lei 4.978 de 1964).

Em seu Art. 100, a lei estabeleceu que o ensino primário seria ministrado em 6 séries anuais nos grupos escolares, em cinco séries nas casas escolares e em 4 séries nas casas isoladas, sendo as últimas direcionadas para "objetivos pré-vocacionais e de orientação profissional”.

Para dar sequência nos estudos, a lei estabelecia o seguinte:

Art. 102 - Aos alunos que concluírem a quinta série do ensino primário, em grupos e casas escolares, ou a quarta série em escolas isoladas, será permitida a inscrição em exame de admissão para ingresso na primeira série do $1^{\circ}$ ciclo dos cursos de ensino médio.

Parágrafo Único - A fim de que se proporcione aos alunos satisfatória educação primária, os programas de ensino para as escolas isoladas, para grupos e casas escolares, terão fixados a sua amplitude e desenvolvimento levando-se em conta as diferenças existentes entre esses tipos de estabelecimentos de ensino (PARANÁ, lei 4.978 de 1964).

O Sistema estadual já previa uma articulação entre o ensino primário e o secundário, conforme indicado no artigo 103:

A sexta série do ensino primário incluirá, além do ensino de técnicas de artes industriais e economia doméstica, as disciplinas obrigatórias de primeira série, do $1^{\circ}$ ciclo dos cursos de grau médio.

Parágrafo Único - Ao aluno que houver concluído a sexta série primária, inclusive com aprovação em exame final das disciplinas obrigatórias da primeira série, do $1^{\circ}$ ciclo do grau médio, será facultado o ingresso na segunda série, do $1^{\circ}$ ciclo de qualquer curso de grau médio, independente de exame de admissão (PARANÁ, lei 4.978 de 1964).

A lei estabelecia o ensino de grau médio como sendo aquele destinado a formação do adolescente, de técnicos e profissionais e de professores para o ensino primário por meio do curso normal.

O ensino secundário, segundo as determinações da lei do Sistema Estadual de Ensino seria ministrado em dois ciclos: $1^{\circ}$ ciclo ou ginasial e $2^{\circ}$ ciclo ou colegial, sendo o primeiro com duração de quatro séries anuais e o segundo de 3 séries, no mínimo. A lei especificou ainda: 
Art. 144 - Após estudos realizados sem observância do regime escolar mediante a prestação de exames de madureza em dois (2) anos, no mínimo, e três (3) no máximo, será permitida:

I - Aos maiores de dezesseis (16) anos, a obtenção de certificados de conclusão do curso ginasial;

II - Aos maiores de dezenove (19) anos, a obtenção de certificados de conclusão do curso colegial; (PARANÁ, lei 4.978 de 1964).

Com relação ao ensino técnico e profissional, os ramos de atividades previstos pela lei eram o industrial, agrícola, comercial e politécnico. Paralelamente a formação profissional, estava prevista a obrigatoriedade de cumprir, também, as disciplinas regulares comuns para todos os cursos de grau médio.

Sobre o curso normal, a legislação estadual estabeleceu o seguinte:

Art. 158 - O ensino normal tem por fim a formação de professores, orientadores, supervisores e administradores escolares e outros especialistas destinados ao ensino primário e pré-primário, e o desenvolvimento e propagação dos conhecimentos técnicos relativos à educação da infância (PARANÁ, lei 4.978 de 1964).

As escolas normais de grau ginasial e colegial poderiam, de acordo com a lei, oferecer o curso normal, compreendendo, além do currículo médio, as disciplinas pedagógicas. Já, para a formação em nível de administração escolar, orientação educacional e aperfeiçoamento, era necessário ter concluído o grau colegial e ter exercido, no mínimo, dois anos à docência. As especializações eram oferecidas somente pelos Institutos de Educação.

Em 1971, já pelas mãos dos militares, houve uma alteração na LDBEN, que reorganizou os níveis de ensino em $1^{\circ}$ e $2^{\circ}$ graus, pela Lei 5.692, de 11 de agosto de 1971 . Conforme indicou Novaes, a nova lei, “institui a profissionalização universal e compulsória para o ensino secundário, assim estabelecendo formalmente a equiparação entre o curso secundário e os cursos técnicos" (2010, p. 26). O discurso governamental era de estimulação do desenvolvimento na economia e de formação técnica para o trabalho na educação. Segundo Queirós:

$\mathrm{O}$ apelo a uma adequação do ensino às necessidades do mundo moderno, do domínio da ciência, da tecnologia e da urgência de um ensino profissionalizante que atendesse e formasse pessoal qualificado para o trabalho, era questão que vinha permeando os discursos governamentais há algum tempo (2013, p. 21029).

Ainda de acordo com Queirós (2013), as críticas ao modelo vigente residiam, especialmente, nos problemas de acesso ao ensino primário e técnico, que não atendiam as urgentes demandas pelas quais o país passava. O teste de admissão também vinha sendo entendido como uma dificuldade desnecessária que acabava tirando muitos da escola. 
Com a nova legislação, o ensino obrigatório passou a ser de 8 anos, correspondendo ao $1^{\circ}$ grau, que passou de 4 para 8 anos, eliminando o teste admissional e unificando o primário com o ginásio. Para essa fase de ensino, a Lei 5.692 incorporou disciplinas de iniciação ao mundo do trabalho e testes vocacionais, preparando os alunos para o ingresso no 2 grau. Conforme salientou Queirós “[...] o aconselhamento vocacional tornou-se parte importante do trabalho desenvolvido pela Orientação Educacional, a partir da lei” (2013, p. 21037).

$\mathrm{O}$ ensino de $2^{\circ}$ grau passou a ser de 3 ou 4 anos, conforme a habilitação profissional escolhida pelos estudantes. A lei instituiu a profissionalização obrigatória no curso de $2^{\circ}$ grau, visando preparar mão de obra para o trabalho nas indústrias e no comércio, que estavam em expansão na época, devido ao ingresso de várias empresas multinacionais.

Para Novaes (2010), as reformas feitas pela lei número 5.692/71 direcionou medidas que visou a contenção do movimento operário e a promoção da formação técnica pretendida pela burguesia industrial. Germano, também instigou nesta reflexão:

O que motivou o Estado a levar adiante um projeto de reforma educacional, num momento em que as demandas organizadas e as mobilizações em favor da educação eram inexistentes? Em se tratando ainda de um Estado que concorreu decisivamente para acentuar a miséria social dos despossuídos, ao adotar políticas restritivas ao trabalho e favoráveis ao capital [...] (2000, p. 164).

O mesmo Germano indicou uma resposta:

[...] a ampliação dos anos de escolarização visa, entre outras coisas, absorver temporariamente a força de trabalho "supérflua", contribuindo, dessa forma, para regular o mercado de trabalho. Visa também atender uma demanda social, pois à medida que o sistema escolar se expande os empregadores tendem a exigir uma elevação dos requisitos educacionais da força de trabalho [...] (2000, p. 165).

Novaes salientou que, na época, o parque industrial do Brasil era composto, em mais de $50 \%$ por transnacionais, e que o modelo capitalista e de subserviência que o Brasil adotava diante do monopólio internacional exigia uma educação voltada para a formação de trabalhadores. Segundo a autora, "o objetivo principal da Lei $\mathrm{n}^{\mathrm{o}} 5.692 / 71$, feita no período da Ditadura Militar era conter o avanço das ideias progressistas de esquerda". A lei, portanto, teve como consequência a "exclusão da população aos níveis mais elevados do ensino" (2010, p. 27).

A industrialização foi a característica capitalista amplamente difundida naquele contexto histórico, contribuindo para que o discurso da necessidade da qualificação profissional, ou seja, qualifica do capital humano, fosse aceito pela população, como condição para o desenvolvimento. Com isso, os movimentos contrários foram considerados subversivos e contra a ordem social. A lei 5.692/71 deu legitimidade a este discurso e, legalizou o sistema vigente. 
Instituições Escolares Estaduais Criadas em Francisco Beltrão no Período do Regime Militar

Francisco Beltrão, em 1960, contava com uma população de 55.496 habitantes, mas nesse número estava incluído as populações dos municípios de Enéas Marques e Salto do Lontra, desmembrados de Francisco Beltrão no início da década de 1960 (Cattelan 2014). Ainda assim, nas décadas seguintes, o município viu crescer significativamente sua população e sua produtividade industrial e comercial, ampliando-se a necessidade da oferta educacional e da implantação de níveis cada vez mais avançados de instrução. Em 1970, segundo material produzido pela Secretaria Municipal de Educação e Cultura de Francisco Beltrão (2007), o município tinha uma população de 36.807 habitantes, em 1980 este número cresceu para 48.762, e, em 1991 chegou a 61.272 habitantes.

Para atender essa demanda de crescimento populacional foram sendo criadas algumas instituições escolares, tanto municipais, quanto estaduais no município de Francisco Beltrão, principalmente depois da Lei 5.692 de 1971, que instituiu a obrigatoriedade de escolarização da $1^{\mathrm{a}}$ a $8^{\mathrm{a}}$ série.

Nosso objetivo nesse texto é apresentar minimamente as instituições criadas pelo Estado do Paraná no município. Dentre as instituições criadas naquele período, quase todas ainda estão em atividades e foram/são de grande relevância para a constituição histórica e cultural de Francisco Beltrão e região.

Para tanto fizemos um breve apanhado histórico destas Instituições públicas estaduais que perpassaram o período do regime militar, deixando sua marca e sua influência na sociedade. Todavia, a forma como cada uma lidou com os ditames do regime e da sociedade de então, é tema demasiado extenso para o propósito deste texto, deixaremos esta análise para outro momento, ficando, por hora, com a caracterização das instituições.

O atual Colégio Estadual Dr. Eduardo Virmond Suplycy - Ensino Fundamental e Médio, de acordo com seu Projeto Político Pedagógico (2017), iniciou suas atividades em 1949, como Escola Isolada. Na época, não havia, ainda, o município de Francisco Beltrão, pertencendo este território ao município de Clevelândia.

Em 1956, foram concluídas as instalações próprias, sendo elevado à categoria de Grupo Escolar, recebendo o nome de Dr. Eduardo Virmond Suplicy, em homenagem ao administrador da Colônia Agrícola Nacional General Osório (CANGO), falecido em 1955, que atuou em vários projetos de desenvolvimento da região.

Em 1976, a instituição, atendendo os pressupostos da reforma do ensino de $1^{\circ}$ e $2^{\circ}$ grau, instituída pela lei 5.692/71, alterou sua denominação para Dr. Eduardo Virmond Suplicy - 
Ensino de $1^{\circ}$ grau. Uma nova alteração em suas modalidades de atendimento educacional só aconteceu após o fim do regime militar, com a municipalização do ensino em 1991. A Escola Municipal Professora Maria Basso Delani assumiu as turmas de $1^{\mathrm{a}}$ a $4^{\mathrm{a}}$ série, e o Suplicy as de $5^{\circ}$ ao $8^{\circ}$ ano. A instituição passou a ofertar, em 1993, o ensino Supletivo de Educação Geral no período noturno, alterando seu nome para Colégio Estadual Dr. Eduardo Virmond Suplicy (PARANÁ, 2017)

O Colégio Estadual Mario de Andrade, foi aprovado, segundo consta em seu Projeto Político Pedagógico (2017), por decreto emitido em 29 de janeiro de 1964, denominado de Ginásio Estadual de Francisco Beltrão. No início, funcionou junto a estrutura do Grupo Escolar Suplicy, atendendo alunos que buscavam demanda pelo ensino de grau secundário. Pouco tempo depois, por meio de uma parceria firmada entre a Secretaria de Educação do Estado e a Congregação das Irmãs Escolares de Nossa Senhora), o Colégio passou a funcionar junto ao prédio do Instituto Nossa Senhora da Glória, sob direção das irmãs (BELLIATO, 2017).

Em 1970, pelo decreto $\mathrm{n}^{\circ}$. 21289, de 14 de outubro, passou a se chamar "Ginásio Estadual Mario de Andrade", em homenagem ao importante literato de mesmo nome. No mesmo ano, em 11 de dezembro, com a criação no então chamado nível científico (atual ensino médio), passou finalmente a ser chamado Colégio Estadual Mario de Andrade.

Em 1973, em atendimento à Lei $n^{\circ} 5.692 / 71$, foram implantadas as primeiras classes de $5^{\text {a }}$ séries regidas pela nova Lei de Diretrizes e Bases da Educação. Em 1975, implantou-se o Ensino Supletivo de $1^{\circ}$ Grau dentro dos princípios da Lei $\mathrm{n}^{\circ}$. 5.692/71, passando o estabelecimento a oferecer três cursos distintos: Fundamental, Supletivo de $1^{\circ}$ Grau, regidos pela Lei $n^{\circ}$. 5.692/71 e Curso Científico, regido pela Lei $\mathrm{n}^{\circ}$. 4024/61. Em 1979, formaram-se as últimas turmas do Curso Científico, que foi extinto a partir dessa data. Em 1980, o Colégio Estadual Mário de Andrade, passa a absorver também o Ensino de $2^{\circ}$ grau, nas três habilitações: Magistério, Auxiliar de Escritório e Técnico em Contabilidade e, com o processo de reorganização, passou a constituir-se num só Estabelecimento de Ensino - Colégio Estadual "Mário de Andrade" - Ensino de $1^{\circ}$ e $2^{\circ}$ Graus, oficialmente através do Decreto $n^{\circ} 2252 / 80$ da Secretaria de Estado da Educação (PARANÁ, 2017, p. 7).

Também visando a implementação das reformas propostas pela lei 5.692/71, o Colégio Estadual Mario de Andrade fez parte, em Francisco Beltrão, do primeiro complexo educacional do município, onde atendia alunos de $5^{\mathrm{a}}$ a $8^{\mathrm{a}}$ série que vinham do Instituto Nossa Senhora da Glória, da Escola Estadual Beatriz Biavatti, que, na época, atendiam apenas os anos iniciais, de $1^{\mathrm{a}}$ a $4^{\mathrm{a}}$ série e de outras instituições municipais que ofertavam o ensino de $1^{\mathrm{a}}$ a $4^{\mathrm{a}}$ série. $^{6}$

\footnotetext{
${ }^{6}$ Com relação ao Colégio Estadual Mario de Andrade, estamos em processo de elaboração de dissertação junto ao programa de Pós-Graduação em Educação, nível de Mestrado, da Universidade Estadual do Oeste do Paraná UNIOESTE. Nesta pesquisa, abordamos as relações da instituição com aspectos relevantes do regime militar. Entendemos que este estudo é de extrema importância para a compreensão dos reflexos práticos e objetivos dos princípios ideológicos preconizados nos discursos e nos textos legais.
} 
O Colégio Estadual Beatriz Biavatti, que também foi uma das unidades do Complexo Educacional de Francisco Beltrão surgiu, de acordo com seu Projeto Político Pedagógico (2011), em 1958, tendo adotado várias denominações nos primeiros anos de atividade, "Grupo Escolar Vila Nova", "Escola Olegário Mariano de Vila Nova", "Grupo Escolar Ney Braga de Vila Nova”. Em 1968, a instituição passou a se chamar “Casa Escolar Professora Beatriz” em homenagem a uma professora falecida do Colégio Nossa Senhora da Glória. O sobrenome dela foi acrescentado no ano seguinte, e em 1970 passou a ser Grupo Escolar Beatriz Biavatti. Em 1974, quando passou a fazer parte do Complexo educacional, a instituição passou a ser denominada "Escola". Ainda durante o período do regime militar, a instituição passou a ofertar o supletivo de $1^{\circ}$ grau em 1981.

Com a municipalização do ensino de $1^{\mathrm{a}}$ a $4^{\mathrm{a}}$, essa fase ficou a cargo da Escola Municipal Pedro Algeri, enquanto a Escola Estadual Beatriz Biavatti passou a atender os alunos de $5^{\circ}$ ao $8^{\circ}$ ano e o Supletivo (PARANÁ, 2011).

Em 1969, foi fundado, no bairro Alvorada, o Grupo Escolar Alvorada. Em 1976, o nome foi alterado para Reinaldo Sass, funcionário da Colônia Agrícola Nacional General Osório (CANGO), falecido em 1974. Esta alteração, foi feita por meio do decreto 2685, de 21 de dezembro de 1976, que estabeleceu o ensino regular e Supletivo de $1^{\circ}$ Grau na instituição.

Em 1989, passou a ofertar o ensino de $2^{\circ}$ Grau Regular com o curso de Educação Geral. Esta possibilidade veio mediante autorização da resolução de $n^{\circ} .1 .777$, de 03 de julho de 1989 . Após o reconhecimento oficial do curso pela resolução $\mathrm{n}^{\circ}$. 4195, de 30 de dezembro de 1991, a instituição passou a ser chamada de Colégio Estadual Reinaldo Sass - Ensino Fundamental e Médio (PARANÁ, 2017). Junto ao Colégio Estadual Reinaldo Sass, após a municipalização em 1991, funcionou a Escola Municipal Professora Maria Helena Vandresen. O município, mais uma vez, assumiu as turmas de $1^{\mathrm{a}}$ a $4^{\mathrm{a}}$ série, enquanto o Colégio estadual ficou com as turmas de $5^{\circ}$ ao $8^{\circ}$ ano e o $2^{\circ}$ grau. Estado e município dividiram a estrutura física até o ano de 2007 , quando a Escola Maria Helena Vandresen se mudou para estrutura própria.

No bairro Cristo Rei, de acordo com Paraná (2008), desde o tempo da colonização do município já existia uma velha casa de madeira onde eram ministradas aulas para as crianças. Por ficar próxima ao Quartel de Infantaria, na época, e da estrutura física do Departamento de Estradas e Rodagem - DER, recebia uma grande demanda de alunos, filhos dos trabalhadores destes órgãos. Assim, pelo decreto no 8.942, de 14 de fevereiro de 1968, surgia o “Grupo Escolar Cristo Rei”. Autorizado seu funcionamento pelo decreto $n^{\circ} 2.685$, de 21 de dezembro 1976, passou a ser denominada de "Escola Estadual Cristo Rei - Ensino de $1^{\circ}$ Grau. Este nível de instrução só foi reconhecido pela resolução nº 2.632, de 19 de novembro de 1981. 
Em 1991, na mesma estrutura, passou a funcionar a Escola Municipal Professor Rubens Amélio Bonato, assumindo as turmas de $1^{\mathrm{a}}$ a $4^{\mathrm{a}}$ série. Em 1999, tendo recebido a concessão para ministrar aulas de Educação para Jovens e Adultos, recebeu o nome de "Colégio Estadual Cristo Rei”.

O crescimento urbano de Francisco Beltrão também estimulou a criação de indústrias em locais um pouco mais afastados do centro, este foi o caso do bairro Pinheirinho, na zona norte da cidade, distante cerca de $7 \mathrm{~km}$ da área central. Neste local, na década de 1980, instalou-se o então chamado frigorífico Chapecó, que levou muitos trabalhadores a fixarem residência em seus arredores. O crescimento da população e da economia do local, com a chegada de outras indústrias e ramos comerciais fez aumentar a necessidade de atendimento educacional. Na época, o ensino de $1^{\circ}$ grau era oferecido na Escola Municipal Casemiro de Abreu. Para outros níveis de escolaridade, os alunos precisavam se deslocar para o centro da cidade. Com o baixo poder aquisitivo dos moradores da região, muitos abandonaram os estudos (PARANÁ, 2017).

Para enfrentar este problema, a direção da escola Casemiro de Abreu, juntamente com professores, funcionários e comunidade local, uniram-se para solicitar a Secretaria Estadual de Educação a oferta de níveis mais avançados de ensino. Mediante a resolução $\mathrm{n}^{\circ} 5.431$, de 10 de dezembro de 1985 foram abertas algumas turmas de $5^{\circ}$ ano em salas compartilhadas com a estrutura municipal. No ano de 1993, trabalhando como uma extensão do Colégio Estadual Reinaldo Sass, passou a ofertar, também, o Ensino Médio. Em 1997, a instituição foi autorizada a ofertar o curso de Educação Geral, tornando-se Colégio Estadual Tancredo Neves - Ensino de $1^{\circ}$ e $2^{\circ}$ grau (PARANÁ, 2017).

Também distante do centro, no distrito de Nova Concórdia, foi criado em 31 de dezembro de 1968, o "Ginásio de Nova Concórdia", mantido pela entidade Campanha Nacional de Educandário Gratuito (C.N.E.G.). Em 1971 passou a ser mantido pelo estado com o nome de “Ginásio Estadual de Nova Concórdia”. Pela resolução no 1415/80, a instituição passou a ser nominada de "Escola Arnaldo Faivro Busato", em homenagem ao deputado que lutou pela estadualização da escola. Somente em 1984 teve seu nome mudado para "Escola Estadual Arnaldo Faivro Busato". A nomenclatura de Colégio só veio bem mais tarde, em 2003, com a implantação do ensino médio.

De acordo com Belliato e Castanha (2016), houve ainda, em Francisco Beltrão, uma outra instituição estadual de ensino que teve sua implantação durante o Regime Militar. Pensada com o intuito de suprir a necessidade de formação mais elevada aos professores da cidade, pelo decreto 19.838, de 27 de outubro de 1965, foi implantada a Escola Normal Colegial Estadual Regina Mundi, tornando-se "uma importante instituição de formação de professoras a partir de 1966" (BELLIATO E CASTANHA, 2016, p. 203). 
Sem ter uma sede própria, segundo os mesmos autores, a escola funcionou em diversas instituições do município. Quando saiu do Colégio Glória "[...] foi pro Castelo da Floresta na ASSESSOAR e de lá [...] um ano na Escola Beatriz Biavati” (BELLIATO E CASTANHA, 2016, p. 203). Depois, foi incorporada a Escola de $2^{\circ}$ Grau "Roberto Antônio Croda", junto a estrutura do Colégio Estadual Eduardo Virmond Suplicy. A lei 5.692 de 1971 reorganizou a estrutura de ensino de $1^{\circ}$ e $2^{\circ}$ grau, estabelecendo a formação de professores em nível de Magistério de $2^{\circ}$ grau, assim, após 1980, foi extinta a modalidade de Escola Normal no município de Francisco Beltrão, sendo incorporada pelo Colégio Estadual Mario de Andrade (BELIATTO E CASTANHA, 2016).

Vimos neste breve relato que foram várias as instituições criadas no período do regime militar, explicitando assim, o rápido crescimento do município de Francisco Beltrão. De todas as instituições criadas no período, somente o Escola Normal Regina Mundi não existe mais, mas a formação por ela desempenhada foi assumida pela modalidade de magistério de $2^{\circ}$ grau, junto ao Colégio Estadual Mario de Andrade.

Como enfatizado anteriormente, nosso objetivo neste texto era somente identificar as instituições de ensino estaduais criadas no município de Francisco Beltrão durante o período do regime militar. Devido ao número de instituições e a extensão do tema, não será possível, neste texto, analisar suas atividades em relação aos ditames do regime, e nem seus percursos históricos, deixamos isso para estudos futuros.

\section{Considerações Finais}

Neste artigo, estudamos as questões históricas, políticas e educacionais que estabeleceram o cenário para a realização do Golpe Militar em 1964. Apresentamos como aspectos relevantes a Guerra Fria que colocava em choque direto as ideias capitalistas, encabeçados pelos Estados Unidos da América e a proposta Socialista vivenciada na União Soviética. Nesse cenário emergiram conflitos ideológicos entre conservadores e liberais, entre nacionalistas e internacionalistas. Este, aliados ao capital imperialista, buscava a todo custo controlar o país, seja por meio do capital internacional, seja pela iniciativa privada e obtiveram êxito, com o golpe militar-civil de 1964.

Também foi preciso compreender os aspectos da legislação educacional que vigoravam no Brasil e no paraná na época, como era organizada a educação primária e secundária e como o Estado regulamentou as bases educacionais. Ficou evidente que o regime militar estimulou uma base educacional com características tecnicistas e de subserviência aos interesses do monopólio econômico internacional e aos industriais brasileiros. 
Também identificamos todas as instituições escolares estaduais criadas em Francisco Beltrão, durante o período do regime militar. Não foi/é nosso objeto, neste momento, desenvolver estudos detalhados sobre as trajetórias destas instituições, mas sim situá-las em seu tempo histórico, deixando essas histórias abetas para outros estudos nossos e dos demais pesquisadores interessados na temática das instituições escolares.

\section{Referências}

AMADOR, Milton Cleber Pereira. Ideologia e legislação educacional no Brasil. Concórdia SC: Universidade do Contestado, 2002.

BELliato, Moacir da Costa. O Colégio Nossa Senhora da Glória e o processo de escolarização no município de Francisco Beltrão - PR (1951 - 1982). Dissertação de Mestrado, Francisco Beltrão, 2017.

BELliATO, Moacir da Costa; CASTANHA, André Paulo. A Escola Normal Colegial Estadual Regina Mundi - 1965 - 1976: Primeiros apontamentos sobre a formação de Professores primários em Francisco Beltrão - PR. Faz Ciência, vol. 18, n. 27, jan/jun de 2016 - p. 191-211.

BRASIL. Lei n ${ }^{\circ}$ 4.024, de 20 de dezembro de 1961. Fixa as diretrizes e bases da Educação Nacional. Disponível em: <http://www2.camara.leg.br /legin/fed/lei/1960-1969/lei-4024-20dezembro-1961-353722-publicacaooriginal-1-pl.html> Acesso em: 22 out. 2018.

BRASIL. Lei $n^{\circ} 5.692$, de 11 de agosto de 1971. Fixa Diretrizes e Bases para o ensino de $1^{\circ}$ e $\mathbf{2}^{\circ}$ graus, e dá outras providências. Disponível em: < http://www2.camara.leg.br/legin/fed/lei/1970-1979/lei-5692-11-agosto-1971-357752-p ublicacaooriginal-1-pl.html> Acesso em: 23 out. 2018.

CAPUCHINHO, Cristiane. 31 de março ou $1^{\circ}$ de abril: Dia do golpe é motivo de disputa. Disponível em: <https://educacao.uol.com.br/noticias/2014/03/27/31-de - marco-ou-1-de-abrildia-do-golpe-e-motivo-de-disputa-ideologica.htm> Acesso em: 12 de setembro de 2019.

\section{CATTELAN, Carla. Educação rural no município de Francisco Beltrão entre}

1948 a 1981: a escola multisseriada. Dissertação de Mestrado, Francisco Beltrão, 2014.

FRANCISCO BELTRÃO. História e Geografia de Francisco Beltrão: educando com o coração. 2. rd. Francisco Beltrão: Secretaria Municipal de Educação Cultura e Esporte, 2007.

GERMANO, José Willington. Estado militar e educação no Brasil. 5. ed. São Paulo: Cortez, 2000.

MARCHELLI, Paulo Sérgio. Da LDB 4.024/61 ao Debate Contemporâneo sobre as Bases Curriculares Nacionais. Revista e Curriculum, São Paulo, v. 12, n. 03 p. 1480 - 1511, out/dez 2014.

NOVAES, Marilda Aparecida. Educação Profissional e Ensino Médio: Separação Versus Integração. 2010. 52 f Monografia (Conclusão de Curso em Pedagogia) - UEL - Universidade Estadual de Londrina, Londrina - 2010.

PARANÁ. Colégio Estadual Arnaldo Faivro Busato - Projeto Político Pedagógico Construção Coletiva, 2010.

PARANÁ. Colégio Estadual Beatriz Biavatti - Projeto Político Pedagógico - Construção Coletiva, 2011. 
PARANÁ. Colégio Estadual Cristo Rei - Projeto Político Pedagógico - Construção Coletiva, 2008.

PARANÁ. Colégio Estadual Dr. Eduardo Virmond Suplicy - Projeto Político Pedagógico Construção Coletiva, 2017.

PARANÁ. Colégio Estadual Mario de Andrade - Projeto Político Pedagógico - Construção Coletiva, 2017.

PARANÁ. Colégio Estadual Reinaldo Sass - Projeto Político Pedagógico -Construção Coletiva, 2017.

PARANÁ. Colégio Estadual Tancredo Neves - Projeto Político Pedagógico - Construção Coletiva, 2017.

PARANÁ. Lei No 4978 de 05 de dezembro de 1964. Estabelece o Sistema Estadual de Ensino. Disponível em: < http://leisestaduais.com.br/pr/lei-ordinaria-n-4978-1964-parana-estabelece-osistema-estadual-de-ensino> Acesso em: 15 jul. 2019.

QUEIRÓS, Vanessa. A lei $\mathbf{n}^{\circ}$ 5692/71 e o ensino de $1^{\circ}$ grau: Concepções e Representações. In: XI Congresso Nacional de Educação. Pontifícia Universidade Católica do Paraná, Curitiba, de 23 a 26 de setembro de 2013, p. $21027-21043$.

Recebido em 05/09/2019. Aprovado em 20/11/2019. 